University of Nebraska - Lincoln

DigitalCommons@University of Nebraska - Lincoln

USDA National Wildlife Research Center - Staff

Publications

U.S. Department of Agriculture: Animal and Plant Health Inspection Service

2009

\title{
Enhancing the Perceived Threat of Vehicle Approach to Deer
}

Bradley F. Blackwell

USDA/APHIS/WS National Wildlife Research Center, bradley.f.blackwell@aphis.usda.gov

Thomas W. Seamans

USDA/APHIS/WS National Wildlife Research Center, thomas.w.seamans@aphis.usda.gov

Follow this and additional works at: https://digitalcommons.unl.edu/icwdm_usdanwrc

Part of the Environmental Sciences Commons

Blackwell, Bradley F. and Seamans, Thomas W., "Enhancing the Perceived Threat of Vehicle Approach to Deer" (2009). USDA National Wildlife Research Center - Staff Publications. 802.

https://digitalcommons.unl.edu/icwdm_usdanwrc/802

This Article is brought to you for free and open access by the U.S. Department of Agriculture: Animal and Plant Health Inspection Service at DigitalCommons@University of Nebraska - Lincoln. It has been accepted for inclusion in USDA National Wildlife Research Center - Staff Publications by an authorized administrator of DigitalCommons@University of Nebraska - Lincoln. 


\title{
Enhancing the Perceived Threat of Vehicle Approach to Deer
}

\author{
BRADLEY F. BLACKWELL, ${ }^{\mathbf{1}}$ United States Department of Agriculture, Animal and Plant Health Inspection Service, Wildlife Services, National \\ Wildife Research Center, Obio Field Station, 6100 Columbus Avenue, Sandusky, OH 44870, USA
}

THOMAS W. SEAMANS, United States Department of Agriculture, Animal and Plant Health Inspection Service, Wildlife Services, National Wildlife Research Center, Ohio Field Station, 6100 Columbus Avenue, Sandusky, OH 44870, USA

\begin{abstract}
In North America and Europe, deer (Cervidae)-vehicle collisions (DVCs) are common and result not only in injury and death to the animals involved, but also human injury and property damage. Given that most DVCs occur during crepuscular periods, we questioned whether the perceived threat to deer posed by vehicle approach could be enhanced. We hypothesized that a vehicle-based lighting system that better complements peak visual capabilities of deer at night relative to standard tungsten-halogen (TH) lighting alone would elicit a greater flight-initiation distance (FID) by free-ranging white-tailed deer (Odocoileus virginianus). Our lighting system comprised 2 TH lamps and one Xenarc high-intensity discharge (HID) lamp. We defined an a priori logistic model comprising 4 variables potentially explaining deer FID relative to vehicle approach: 1) starting distance of the approach, 2) lighting treatment, 3) season, and 4) deer group size. Deer exposed to the combination of TH lamps and constant illumination of the HID lamp exhibited a mean (SD) FID of 136 (127) m. In contrast, deer exposed to TH lamps only initiated flight on average at 116 (127) $\mathrm{m}$, and those exposed to the combination of TH lamps and the HID lamp pulsed at 2 $\mathrm{Hz}$ exhibited a mean FID of 89 (98) $\mathrm{m}$. We contend that the pulsing of the HID lamp while TH lamps were illuminated resulted in consistent loss (over approx. 0.5 -sec intervals) of a portion of the image on approach, possibly interfering with sensory information relative to the position of the potential threat. In contrast, the combination of TH lamps and constant illumination of the HID lamp contributed $(P=0.033)$ to the probability of a FID $\geq 94 \mathrm{~m}$. We suggest, therefore, that deer FID can be increased by combining currently available TH and HID lamps, or use of HID lamps alone, to enhance detection of an approaching vehicle at night. Also, we encourage research into new lamp designs to better complement deer visual capabilities as well as continued research to quantify deer FID in response to vehicle approach at night and lampspecific properties that can enhance deer detection of the vehicle. (JOURNAL OF WILDLIFE MANAGEMENT 73(1):128-135; 2009)
\end{abstract}

DOI: $10.2193 / 2008-014$

KEY WORDS deer-vehicle collisions, deer vision, flight-initiation distance, Odocoileus virginianus, vehicle-based lighting, white-tailed deer.

Approximately 1.5 million deer (Cervidae)-vehicle collisions (DVCs) occur each year in the United States and result in $\geq$ US $\$ 1.1$ billion in damage, injuries to occupants, and loss of individual animals (Conover et al. 1995, Insurance Institute for Highway Safety 2005). In Sweden, reports indicate an average of 10,000 vehicle collisions with moose (Alces alces) and 51,000 collisions with roe deer (Capreolus capreolus) annually (Seiler et al. 2004). Contributing factors to DVCs include species population demographics (Bellis and Graves 1971, McCaffery 1973, Allen and McCullough 1976), activity patterns (Allen and McCullough 1976, Biggs et al. 2004; see also Kammermeyer and Marchinton 1977, Hayes and Krausman 1993), habitat features (Bellis and Graves 1971, Bashore et al. 1985, Finder et al. 1999, Seiler 2005; see also review by D'Angelo et al. 2004), and traffic volume and speed (Allen and McCullough 1976, Bashore et al. 1985, Seiler 2005). Further, recent predictive models, based on site-specific DVC data and tested against independent DVC sites, emphasize the importance of cover proximate to roads and road density in high-cover landscapes as explanatory variables in rates of DVCs (Seiler 2005, Hussain et al. 2007).

Habituation to vehicle traffic likely reduces the perception of threat to deer posed by vehicles. However, there is potential for the threat perceived by deer to be enhanced (e.g., Ydenberg and Dill 1986, Frid and Dill 2002,

${ }^{1}$ Email: bradley.f.blackwell@aphis.usda.gov
Stankowich and Blumstein 2005). For example, in a test of Helfman's (1989:48) "threat sensitivity hypothesis" flight distance of Columbian black-tailed deer (Odocoileus hemionus columbianus) increased relative to an increased pace of an approaching human and the directness of the approach (Stankowhich and Coss 2006). Here, time spent assessing the threat decreased with approach speed but was positively associated with the distance at which the deer first became alert (i.e., alert distance). We questioned, therefore, whether the potential threat to deer posed by the appearance of an approaching vehicle might also be enhanced.

Specifically, given the crepuscular activity patterns in deer and the predominance of DVCs during periods of low ambient light (noted above), a logical means of potentially enhancing the threat posed to deer by an approaching vehicle is through vehicle-based lighting treatments. To date, there is no indication in the literature that DVCs are necessarily influenced by vehicle lamps. More specifically, research quantifying the behavioral response of deer to lighting that broadly corresponds to deer visual capability during periods of low ambient light has not been reported (see reviews by D'Angelo et al. 2004, Hedlund et al. 2004, Curtis and Hedlund 2005).

Deer are not necessarily visually hindered at night; thus, vision remains an important component of vigilance. For example, the large, side-facing eyes with horizontal macula of the white-tailed deer (O. virginianus; Dukes 1969) allow for both peripheral and binocular vision, providing approx- 
imately $310^{\circ}$ of horizontal vision. Eyelids regulate light entry to increase or, in the case of vehicle lamps, decrease the number of photoreceptors exposed (J. Neitz, The Eye Institute, Milwaukee, WI, unpublished report; Walls 1942; VerCauteren and Pipas 2003). White-tailed deer and fallow deer (Dama dama) are dichromatic in that the retina contains 3 classes of photopigment, a short-wavelengthsensitive (SWS) cone $\left(\lambda_{\max }=450-460 \mathrm{~nm}\right)$, a middlewavelength-sensitive (MWS) cone $\left(\lambda_{\max }=537 \mathrm{~nm}\right)$, and rod pigment $\left(\lambda_{\max }=497 \mathrm{~nm}\right.$; Jacobs et al. 1994). However, $90 \%$ of photoreceptors within the retina are rods, thus providing deer with a visual capability that is sensitive in dim light. In addition, like other mammals active at night, deer possess a tapetum lucidum, which reflects incidental light back through the retina (i.e., through the photopigment a second time), further enhancing vision in dim light (Dukes 1969).

We hypothesized that a vehicle-based lighting system that better complements the visual capabilities of deer at night (i.e., within $400-537 \mathrm{~nm}$ ) relative to tungsten-halogen $(\mathrm{TH})$ lighting alone, would elicit a greater flight-initiation distance (FID; Walther 1969, Stankowich and Coss 2006) in response to vehicle approach. Our objective was to model real-time avoidance of an approaching vehicle by freeranging white-tailed deer.

\section{STUDY AREA}

We conducted our experiment at the National Aeronautics and Space Administration's (NASA) Plum Brook Station (PBS), Erie County, Ohio, USA $\left(41^{\circ} 22^{\prime} \mathrm{N}, 82^{\circ} 41^{\prime} \mathrm{W}\right)$. The 2,200-ha PBS was enclosed by a 2.4-m-high chain-link fence with barbed-wire outriggers. Habitat within PBS differed from the surrounding mix of agricultural and suburban area, comprising canopy-dogwood (Cornus spp.; $39 \%$ ), old field and grasslands $(31 \%)$, open woodlands $(15 \%)$, and mixed-hardwood forests $(11 \%)$ interspersed by abandoned and actively used structures relating to NASA and prior operations and paved roads that circle and bisect the station. Deer ingress and egress occurred through several gaps between the fence and ground. Further, deer on PBS were routinely exposed to vehicles during daylight hours and, to a lesser degree, at night. In addition, roads on PBS were generally bordered by a mown strip approximately 30 $\mathrm{m}$ wide, reducing the potential for DVCs due to visual obstruction near the roadside. Estimated deer density during winter 2005 through 2006 was 52 animals $/ \mathrm{km}^{2}$ (J. Cepek, United States Department of Agriculture, Wildlife Services, unpublished data).

\section{METHODS}

In the context of a semi-controlled experiment with freeranging deer, inference as to effects of lamp type on animal behavior, while controlling for emission spectrum and spectral irradiance (i.e., power incident upon a surface/ wavelength; $\mu \mathrm{W} / \mathrm{cm}^{2} / \mathrm{nm}$ ), is not possible. Each type of vehicle lamp has its own spectral properties whose levels cannot be controlled separately. Further, animal photo- receptors respond to photons independent of energy (Endler 1990). Therefore, the perceived brightness or total intensity of light (i.e., photon or quantum flux; $\mu \mathrm{mol} / \mathrm{m}^{2} / \mathrm{sec}$ ) by deer from vehicle lamps during approach is dependent upon 1) power to the lamp, which heats the filament or charges gas molecules, thus affecting the lamp emission spectrum; 2) light reflectance and transmission (affected by, e.g., lamp emission power, relative humidity, dust) to the eye; 3) light transmission, refraction, and photoreception within the eye; and 4) neural processes that lead to the perception of light (Endler 1990).

We combined the properties of 2 lamp types similar in total spectral irradiance but differing in emission spectrum. The combination allowed us to modulate the amount of absolute and proportionate spectral irradiance within 400 $\mathrm{nm}$ to $537 \mathrm{~nm}$, the range that includes the SWS and MWS cones as well as peak absorption for the rod pigment in white-tailed deer (Neitz and Jacobs 1989, Jacobs et al. 1994). We did not convert our lamp energy measurements to quantum flux (i.e., $\mu \mathrm{mol} / \mathrm{m}^{2} / \mathrm{sec}$ ). Therefore, our lamp metrics serve only as indices of light conditions to which we exposed individual deer.

Our treatments comprised 1) $2 \mathrm{TH}$ lamps only, 2) $2 \mathrm{TH}$ lamps with a high-intensity discharge (HID) lamp set to a 2$\mathrm{Hz}$ pulse rate, and 3) $2 \mathrm{TH}$ lamps with constant HID lamp illumination. Consistent use of the TH lamps provided a condition of safety for the observers during travel, a lighting regimen common to vehicle traffic at night on PBS, and a standard by which we could evaluate addition of HID lamp treatments. Pulse treatment allowed us to modulate the spectral irradiance between TH lamps alone and TH lamps with constant HID lamp illumination. Therefore, in addition to comparing behavioral responses between $\mathrm{TH}$ lamps alone and the combined system, we were able to evaluate behavioral response to a disruption in sensory information from the HID lamp (e.g., Dean et al. 1989).

On each night of the experiment, we randomized treatment order before beginning observations. In addition, because we worked with free-ranging deer and thus could not guarantee balanced observations among treatments, we adjusted treatment orders to balance observations.

We used a Ford F-250 pickup truck (Ford Motor Co., Dearborn, MI) as our approach vehicle. General Electric (Cleveland, OH) sealed-beam TH (Type 2B1; 13-V; 65-W) lamps were installed on the truck at the factory. The TH lamp has been standard equipment in American-made vehicles for 3 decades. Light from the TH lamp is generated thermally and is more yellow than daylight (i.e., a greater proportion of the emission spectrum is $>550 \mathrm{~nm}$ ).

We fitted the truck with a rack above the cab and a 35watt Osram (Munich, Germany) D1S Xenarc ${ }^{\text {TM }}$ HID lamp (Fig. 1). Light from the HID lamp is not produced by the heating of a filament, but instead charged gas (xenon) in the bulb generates the emission spectrum, which comprises more wavelengths in the blue region (i.e., $<450-495 \mathrm{~nm}$ ). Also, we connected the HID lamp to the pulse-control device, the Pulselite ${ }^{\mathrm{TM}}$ (Precise Flight, Inc., Bend, OR), 


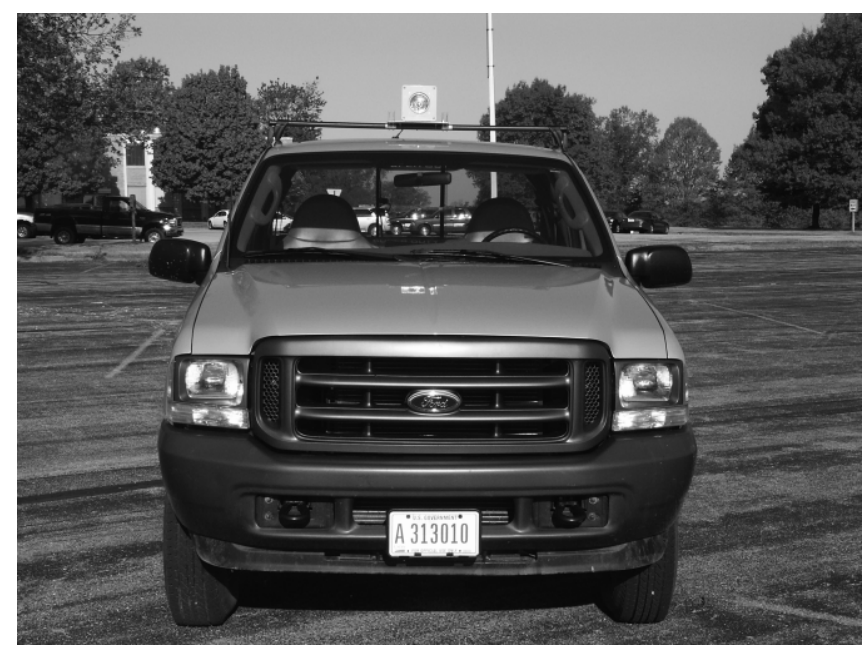

Figure 1. Ford F-250 pickup truck (Ford Motor Co., Dearborn, MI) used during an experiment (1 Feb-30 Oct 2006, Erie County, OH, USA) that exposed free-ranging white-tailed deer to the truck's approach while exhibiting one of 3 lighting treatments: 1) tungsten-halogen (TH) lamps only, 2) TH lamps with a high-intensity discharge (HID) lamp set to a 2$\mathrm{Hz}$ pulse rate, or 3) $\mathrm{TH}$ lamps with constant HID lamp illumination. General Electric (Cleveland, OH) sealed-beam TH (type 2B1; 13-V, 65W) lamps were installed on the truck at the factory. A 35-watt Osram (Munich, Germany) D1S Xenarc ${ }^{\mathrm{TM}}$ HID lamp was installed on the cab.

which included a built-in meter by which we monitored the pulse rate $(\mathrm{Hz})$ of the lamp. The HID lamp and the Pulselite were powered by connection to a 10-amp outlet in the truck.

We used a USB2000 fiber optic spectrometer (Ocean Optics, Inc., Dunedin, FL) and Ocean Optics SpectraSuite Spectroscopy Platform software (Version NetBeans IDE 4.1) to quantify lamp spectra. For this component, we selected a night without moonlight or snow cover and positioned the truck on a level, paved road $100 \mathrm{~m}$ from the spectrometer. We horizontally secured the probe, connected to a 2-m-long, 400- $\mu \mathrm{m}$-diameter fiber optic cable, to a vertical mount $102 \mathrm{~cm}$ above the ground (approx. eye level of a white-tailed deer), and directed it toward the truck. We recorded spectral irradiance at an integration time of 14.34 milliseconds, with boxcar width set to zero.

We began our experiment on 1 February 2006 with the goal of one randomly selected night of data collection per week over 1 year. We collected data only on nights when visibility was clear and the road surface was dry, thus preventing additional noise on approach due to the wet road surface or the effects of snow and ice. In addition, we attempted to limit our data collection to nights when wind speed was $\leq 16 \mathrm{~km} / \mathrm{hour}$.

We selected a $32-\mathrm{km}$ paved route that bounded most paved roads interior to PBS and sampled the mix of habitats represented. The route was intersected by multiple paved roads that crossed the facility, thus affording greater opportunity for deer contacts, as well as means of spatially separating our experimental approaches so as to reduce the likelihood of double sampling within the same evening. Specifically, we reduced the likelihood of double sampling on the same night by adherence to the preplanned route, noting direction of travel for animals responding to the approach, and foregoing approaches on roads immediately adjacent to the site of a preceding approach (a distance of approx. $152 \mathrm{~m}$ ). Also, we restricted our observations to one approach on roads where our treatment was potentially visible to animals $\leq 1 \mathrm{~km}$ distance and on the same road.

A driver and observer were present each night. Observations began after dark, $\geq 30$ minutes after sunset. Our protocol each night comprised the random selection of travel direction along the $32-\mathrm{km}$ route. While we were on the route and during all approaches to a target animal or group, the TH lamps were illuminated on high beam. We used a Raytheon (Waltham, MA) forward-looking infrared (FLIR) Nightsight Palm IR 250 digital camera, mounted on the passenger side window, to scan ahead of the vehicle for deer. When we detected one deer or group on or within $15 \mathrm{~m}$ of the road edge, the observer noted the location of the deer relative to the road and directed the driver to drop a marker noting the start point. The driver then activated the preselected HID treatment (if called for in the treatment order) and began the approach. The driver accelerated to a constant speed of $40.2 \mathrm{~km} /$ hour for the approach. We recognized that approach speed is a critical component in how a prey species interprets the intensity of threat posed by a predator (Ydenberg and Dill 1986, Stankowich and Blumstein 2005) and that the potential behavioral effect from the initial acceleration might differ with distance (e.g., Stankowich and Coss 2006). Therefore, we recorded starting distance for each approach and included the variable in our modeling.

Our ability to accurately and consistently quantify aspects of alert behavior by an individual or group was hampered by the need to make observations at night, via the FLIR camera, and while in a moving vehicle. We therefore defined our response variable as a behavior that would eventually take an individual deer away from the road and contact with the road edge (i.e., avoiding collision) or flight away from its initial off-road position, before the truck was perpendicular with the position of the individual or central point of the group at initial sighting. At the instant a deer initiated movement to avoid the truck, the observer alerted the driver to drop a marker. When approaching a group, we recorded data for as many individuals in the group as possible. We considered the approach complete when an individual or group avoided the truck, the truck was forced to stop to avoid collision, or we observed no reaction up to the point in which the truck was perpendicular to the individual or group.

Subsequent to each approach, we recorded the distance between the marker denoting the moment of reaction and the original position of the deer or central point of the group, defined as the FID, and the distance between the original position of the deer and the approach starting point on the transect (i.e., the starting distance). We used a Bushnell (Overland Park, KS) Yardage Pro 1000 laser ranging system to record distance and a correction factor of $1.8 \mathrm{~m}$ for the forward speed of the marker when dropped. Because of limitations in accurately measuring the original 
position of a deer or group at distances $>1 \mathrm{~km}$, we recorded the starting distance as 1,001 $\mathrm{m}$ for these approaches. If an individual or group failed to react or the reaction resulted in failure to avoid collision (as defined above) we recorded the FID as $0 \mathrm{~m}$.

In addition to distance data, we recorded group size, distance from the road at initial sighting, wind index (Beaufort scale), and season. We recognized that gender could affect FID, but accurate and consistent identification of gender was not possible, given the constraints on our observations (noted above). Instead, we included a season component to our model in which gender effects (particularly associated with breeding) on FID might be expressed. We also referenced data from the United States National Oceanic and Atmospheric Administration Weather Service Forecast Office (Cleveland, OH) for daily mean wind speeds. We defined season relative to solar calendar (i.e., spring: 22 Mar-21 Jun, summer: 22 Jun-21 Sep, autumn: 22 Sep-21 Dec, winter: 22 Dec-21 Mar).

As noted earlier, PBS comprised a mix of habitat types, which our route sampled. However, replication of habitat effects within the context of PBS was not possible. We, therefore, did not include habitat classification in our analysis.

\section{Experimental Constraints and Inference}

Real-time evaluation of the behavior of free-ranging deer to our experimental treatments was affected statistically by the likelihood of prior exposure to vehicles, repeated exposure of individuals to the same experimental protocol, and our limited control for location and sample size within treatment. Also, individual deer were exposed to both control (i.e., TH lamps only) and treatment approaches (TH lamps and HID lamp-specific treatment) repeatedly over the duration of the experiment (i.e., resulting in dependence between observations within and, possibly, among treatments). However, as noted above, our experimental protocol reduced the likelihood of double sampling on the same night. Further, our adherence to at most one night of experimental approaches per week reduced the effect of multiple observations on the same individuals within and among treatments.

We assumed that the probability for observing behavior of experimentally naïve individuals was equivalent among treatments over time. However, to control for naïve behavior by fawns in response to vehicle approach (i.e., differential vigilance from that of adults; Lung and Childress 2007) we excluded observations of known fawns (during spring and summer). We considered the effect of dependence of observations within and among treatments, as well as the potential effect of the periodic exposure of naïve individuals, as constant among treatments over time. However, the lack of replication across multiple herds dictates that our inference is relative to the PBS.

\section{Analysis}

We summarized our data relative to date, season, treatment, and an approach identification number within date. Because of dependence in reaction among group members (e.g., Lingle and Wilson 2001), we calculated the mean FID per group. We included only approaches in which the individual or group was standing (i.e., not bedded).

Our starting distances ranged from $94 \mathrm{~m}$ to $>1,000 \mathrm{~m}$. We therefore selected the 94-m mark as an arbitrary minimum FID. We modeled the probability of an individual or group exhibiting a minimum FID as a binary response (i.e., FID $\geq 94 \mathrm{~m}=1, \mathrm{FID}<94 \mathrm{~m}=0$ ) and relative to a logistic function. We developed an a priori logistic model of deer response to vehicle approach based on published research examining deer vigilance behavior (Marchinton and Hirth 1984, LaGory 1987, Lingle and Wilson 2001) and expressed the model as

$$
P_{\mathrm{F}}=1 / 1+\exp \left[-\left(\beta_{0}+\beta_{\mathrm{sd}}+\beta_{\mathrm{t}}+\beta_{\mathrm{s}}+\beta_{\mathrm{gs}}\right)\right],
$$

where $P_{\mathrm{F}}$ is the probability of flight response (i.e., $P_{\mathrm{F}}=1$ ). Here, $\beta_{0}$ represents the intercept, and the subsequent $\beta$ values the coefficients (to be estimated) for the specific predictor variables within the exponent. Specifically, sd is the starting distance from the individual or group, $t$ is the lighting treatment, $\mathrm{s}$ is season, and gs is group size.

We obtained parameter estimates for the model using PROC GENMOD and repeated-measures regression on the binary data via generalized estimating equations (SAS Institute, Cary, NC). Because our inference pertained to deer on PBS over time, not concurrent sampling of separate herds over time, we could leave within-subject variance for the repeated-measures analysis as undefined. However, we selected date of observation as the subject and used an autoregressive correlation structure (Hedeker and Gibbons 2006). Also because of the lack of experimental replication across multiple herds of white-tailed deer, we did not evaluate the fit of multiple a priori candidate models (e.g., Burnham and Anderson 2002). Instead, we report descriptive statistics and model results only. We considered a parameter as contributing significantly to a model when $P \leq$ 0.05 .

We mention product names solely to report factually on available data; our mention of companies or commercial products does not imply recommendation or endorsement by the United States Department of Agriculture (USDA) over others not mentioned. Also, our procedures were approved by the USDA, Animal and Plant Health Inspection Service, Wildlife Services, National Wildlife Research Center (NWRC), Institutional Animal Care and Use Committee prior to the start of our study.

\section{RESULTS}

The TH lamps produced a spectrum (Fig. 2A) that fell toward the middle wavelengths (max. spectral irradiance [MSI] at $571.82 \mathrm{~nm}$; total spectral irradiance [TSI] 400-700 $\left.\mathrm{nm}=1.44 \times 10^{6} \mu \mathrm{W} / \mathrm{cm}^{2} / \mathrm{nm}\right)$. Also, $31.8 \%\left(0.46 \times 10^{6}\right.$ $\mu \mathrm{W} / \mathrm{cm}^{2} / \mathrm{nm}$ ) of TSI occurred from $400 \mathrm{~nm}$ to $537 \mathrm{~nm}$ (spanning sensitivities of the SWS and MWS cones and peak absorption for rod pigment; Neitz and Jacobs 1989, Jacobs et al. 1994; Fig. 2A). 


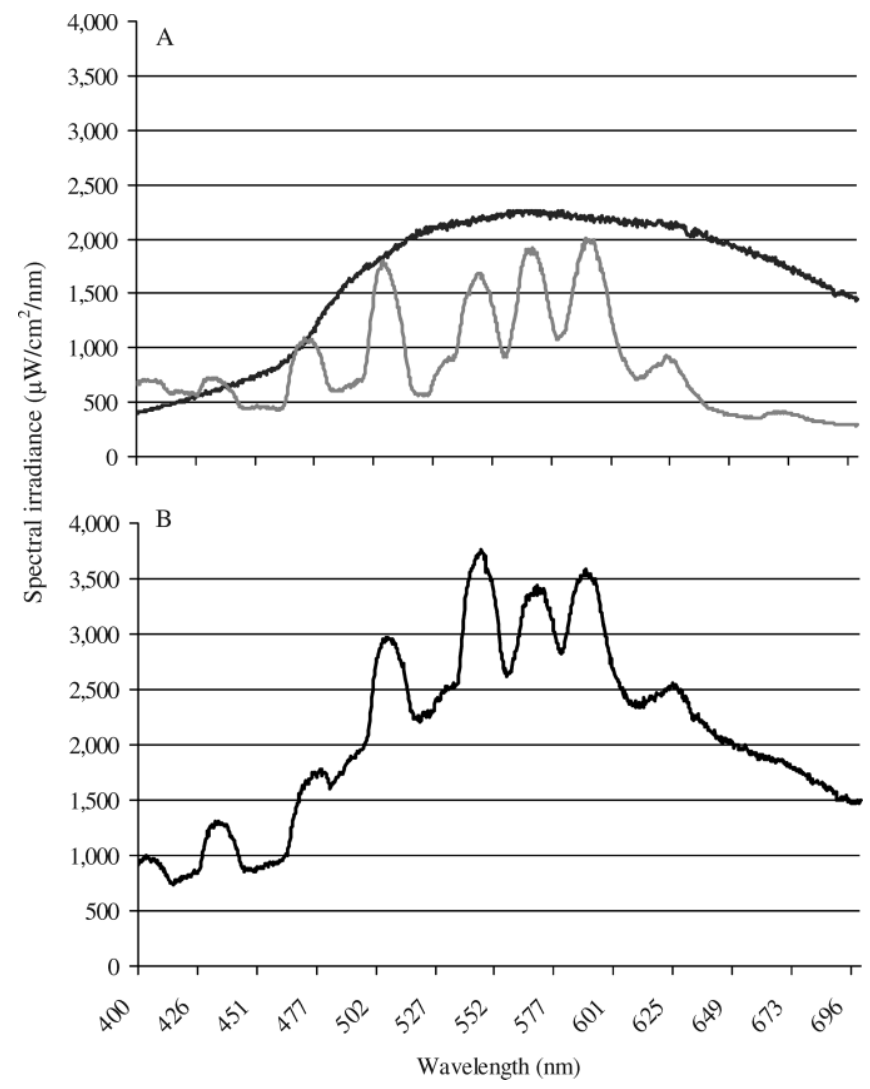

Figure 2. (A) Emission spectrum (smooth curve) from 2 General Electric (Cleveland, $\mathrm{OH}$ ) sealed-beam tungsten-halogen (TH; type 2B1, 13-V, 65W) lamps and one 35-watt Osram (Munich, Germany) D1S Xenarc ${ }^{\text {TM }}$ high-intensity discharge (HID) lamp (peaked curve), and (B) emission spectrum from the combination of the 3 lamps. Lamps were used during an experiment (1 Feb-30 Oct 2006, Erie County, OH, USA) that exposed free-ranging white-tailed deer to an approaching vehicle exhibiting one of 3 lighting treatments: 1) tungsten-halogen (TH) lamps only, 2) TH lamps with a HID lamp set to a $2-\mathrm{Hz}$ pulse rate, or 3) $\mathrm{TH}$ lamps with constant HID lamp illumination.

The HID lamp better approximated full-spectrum light (MSI at $476.41 \mathrm{~nm}$; TSI $400-700 \mathrm{~nm}=0.74 \times 10^{6} \mu \mathrm{W} /$ $\left.\mathrm{cm}^{2} / \mathrm{nm}\right)$, including approximately $40.4 \%\left(0.30 \times 10^{6} \mu \mathrm{W} /\right.$ $\mathrm{cm}^{2} / \mathrm{nm}$ ) of TSI from $400 \mathrm{~nm}$ to $537 \mathrm{~nm}$ (Fig. 2A). Thus, the HID lamp produced a TSI that was $>51 \%$ of the TH lamps combined and better complemented the SWS and MWS cones and rod pigment within the retina of whitetailed deer.

The combination of TH lamps with the HID lamp on constant illumination yielded an MSI at $546.46 \mathrm{~nm}$ and an increase in TSI by $27.5 \%\left(\mathrm{TSI}=1.83 \times 10^{6} \mu \mathrm{W} / \mathrm{cm}^{2} / \mathrm{nm}\right.$; Fig. 2B). In addition, approximately $33.8 \%\left(0.62 \times 10^{6}\right.$ $\mu \mathrm{W} / \mathrm{cm}^{2} / \mathrm{nm}$ ) of the combined TSI was from $400 \mathrm{~nm}$ to 537 $\mathrm{nm}$. Also, the combined system increased the absolute amount of spectral irradiance $(400-537 \mathrm{~nm})$ by $34.8 \%$. The $2-\mathrm{Hz}$ pulse of the HID lamp modulated the spectrum between the TH lamps (Fig. 2A) and the combined spectra (Fig. 2B).

We obtained 31 weeks of observations over a 40 -week period (1 Feb-30 Oct 2006). Missing weeks of observations within the 40 weeks, as well as an extension through 1 year, were due to weather conditions and our restriction of observations during and after a controlled hunt on PBS in November. We conducted 121 vehicle approaches and obtained mean (SD) observations of 60.7 (5.8) individuals per treatment (TH lamps only: 54 deer, TH lamps and HID lamp pulsed at $2 \mathrm{~Hz}$ : 63 deer, TH lamps and constant illumination of HID lamp: 65 deer). Group size across treatments generally exceeded 2 animals per approach, yielding a nearly equal adjusted sample size per treatment (Table 1). Also, across seasons we observed little variation in mean $(\mathrm{SD})$ group size (winter $=2.1[1.3]$ deer, spring $=2.0$ $[0.9]$ deer, summer $=1.6[1.2]$ deer, autumn $=1.7[1.0]$ deer).

Across treatments our average (SE) starting distance for an approach was 420.1 (67.3) $\mathrm{m}$ from an individual or group, but the coefficient of variation ranged from 0.54 to 0.60 per treatment (Table 1). We observed a mean (SE) FID, across treatments, of $113.4(23.6) \mathrm{m}$, but as with starting distance, the coefficient of variation was large (0.94-1.10; Table 1). However, a downward trend in FID across treatments indicated possible habituation to our experimental approaches during the last half of the experiment (winter: $111.7 \pm 92.8 \mathrm{~m}$, spring: $206.5 \pm 151.3 \mathrm{~m}$, summer: $83.3 \pm$ $99.8 \mathrm{~m}$, autumn: $58.5 \pm 73.3 \mathrm{~m}$ ). Within treatment, seasonal mean (SD) FID peaked in spring, then by autumn generally declined to $31.3 \%(13.0 \%)$ of spring observations (Table 2). We obtained $\geq 20$ observations across seasons; however, our adjusted sample sizes per treatment within season were unbalanced (Table 2).

Our model (Table 3) was based on our measure of 54 FIDs at $\geq 94 \mathrm{~m}$, from an adjusted total of 110 vehicle approaches across treatments. Contrary to expectations based on prior work with deer and response to threat, starting distance had no effect on FID. Further, probability of an FID $\geq 94 \mathrm{~m}$ was higher when individuals were exposed to the combination of

Table 1. Mean group size, adjusted treatment samples size, mean vehicle starting distance, and mean flight-initiation distance (FID) recorded during an experiment (1 Feb-30 Oct 2006, Erie County, OH, USA) that exposed free-ranging white-tailed deer to an approaching vehicle exhibiting one of 3 lighting treatments: 1) tungsten-halogen (TH) lamps only, 2) TH lamps with a high-intensity discharge (HID) lamp set to a 2-Hz pulse rate, or 3) TH lamps with constant HID lamp illumination.

\begin{tabular}{lccccrrr}
\hline \multicolumn{1}{c}{ Treatment } & Group size & SD & $\boldsymbol{n}^{\mathbf{a}}$ & Starting distance (m) & SD & FID (m) & SD \\
\hline TH lamps only & 2.1 & 1.3 & 37 & 497.8 & 300.1 & 115.6 & 127.3 \\
TH lamps with HID lamp pulsed at 2 Hz & 2.5 & 1.2 & 37 & 383.1 & 233.1 & 88.7 \\
TH lamps and HID lamp on constant & 2.7 & 1.6 & 36 & 379.5 & 206.2 & 135.8 & 126.8 \\
\hline
\end{tabular}

${ }^{a}$ Sample size within treatment represents data summarized relative to date and approach identification number (individual or group) within date. Because of lack of independence in reaction among group members, we calculated a mean FID per group. 
Table 2. Mean flight-initiation distance (FID; m), by treatment and season (solar calendar), recorded during an experiment (1 Feb-30 Oct 2006 , Erie County, OH, USA) that exposed free-ranging white-tailed deer to an approaching vehicle exhibiting one of 3 lighting treatments: 1 ) tungsten-halogen (TH) lamps only, 2) TH lamps with a high-intensity discharge (HID) lamp set to a 2-Hz pulse rate, or 3) TH lamps with constant HID lamp illumination.

\begin{tabular}{|c|c|c|c|c|c|c|c|c|c|c|c|c|}
\hline \multirow[b]{2}{*}{ Treatment } & \multicolumn{3}{|c|}{ Winter } & \multicolumn{3}{|c|}{ Spring } & \multicolumn{3}{|c|}{ Summer } & \multicolumn{3}{|c|}{ Autumn } \\
\hline & FID & SD & $n^{\mathrm{a}}$ & FID & SD & $n^{\mathrm{a}}$ & FID & SD & $n^{\mathrm{a}}$ & FID & SD & $n^{\mathrm{a}}$ \\
\hline TH lamps only & 86.8 & 94.3 & 5 & 211.1 & 142.7 & 11 & 91.0 & 116.3 & 12 & 47.6 & 72.4 & 9 \\
\hline TH lamps with HID lamp pulsed at $2 \mathrm{~Hz}$ & 80.0 & 65.8 & 13 & 125.2 & 126.5 & 7 & 87.0 & 116.9 & 13 & 58.2 & 74.8 & 4 \\
\hline TH lamps and HID lamp on constant & 160.6 & 105.5 & 11 & 292.7 & 164.7 & 6 & 71.6 & 62.8 & 12 & 72.6 & 82.4 & 7 \\
\hline$n^{\mathrm{a}}$ & & & 29 & & & 24 & & & 37 & & & 20 \\
\hline
\end{tabular}

${ }^{a}$ Adjusted sample size within and across treatments by season represents data summarized relative to date and approach identification number (individual or group) within date.

TH lamps and constant illumination of the HID lamp (e.g., TH lamps and HID lamp on constant: $P_{\mathrm{F}}=0.26$, other treatments: $P_{\mathrm{F}}<0.12$, assuming season $=$ Aug, group size $=$ 3 deer, starting distance $=200 \mathrm{~m}$ ). Our pulse treatment had no estimable effect on FID nor did the parameter winter. However, the parameters autumn and group size contributed to decreased FIDs; also, the parameter summer contributed marginally to decreased FIDs.

Because of unbalanced sample sizes per treatment (Table 2), we did not pursue a posteriori analyses of treatment effects on FID within season. However, for approaches conducted during winter, group size was negatively correlated with FID (estimate $=1.0754, \mathrm{SE}=0.5345, Z=$ $-2.01, P=0.044)$ and starting distance contributed marginally to FID (estimate $=0.0071, \mathrm{SE}=0.0037, Z=$ $1.94, P=0.053)$. We found no other within-season effects for either variable.

\section{DISCUSSION}

We demonstrated that a vehicle-based lighting system that better complements peak visual capabilities of white-tailed deer at night (i.e., via total and proportionate spectral irradiance within 400-537 nm) than standard TH lamps alone yielded a greater FID by free-ranging deer. Effects of our treatments on deer FID within season were unclear because of unbalanced data but likely also because genderand age-specific energetic and physiological demands that affect behavior (Verme and Ullrey 1984) were not necessarily synchronous with our definition of season. In addition, in the last half of the experiment we detected evidence of habituation that could have overshadowed other factors affecting FID. We discuss each of these areas in succession.

It is intuitive to assume that a vehicle-based lighting system that is more readily detected by deer might contribute to a greater FID. Indeed, our results support this assumption. However, our inability to make comparisons between different lamp emission spectra within 400 $\mathrm{nm}$ to $537 \mathrm{~nm}$, but at comparable measures of spectral irradiance measures, brings into question the relative benefit of each factor to increasing deer FID. Although behavioral data in response to these specific lamp properties (and, particularly, the levels of quantum flux within $400-537 \mathrm{~nm}$ ) are critical to new designs, our findings indicate that deer FID can be increased by the combination of currently available lamp products and, possibly, HID lamps used alone.

Further, we suggest that our pulse treatment, involving the pulsing of the HID lamp while TH lamps were illuminated, resulted in the consistent loss to deer (over approx. 0.5-sec intervals) of a portion of the image on approach, possibly interfering with sensory information relative to the position of the potential threat. For example, cells within the superior colliculus of several mammalian species (e.g., rats [Rattus rattus]) receive visual sensory information and respond primarily to object appearance, disappearance, and approach (Dean et al. 1989). If a stimulus provides sufficient information to signal threat (e.g., an object on collision

Table 3. Parameter estimates for an a priori model explaining the flight-initiation distance $(\geq 94 \mathrm{~m})$ of free-ranging white-tailed deer recorded during an experiment (1 Feb-30 Oct 2006, Erie County, OH, USA) that exposed the deer to an approaching vehicle exhibiting one of 3 lighting treatments: 1) tungsten-halogen (TH) lamps only, 2) TH lamps with a high-intensity discharge (HID) lamp set to a 2-Hz pulse rate, or 3) TH lamps with constant HID lamp illumination. We obtained parameter estimates for the model using SAS PROC GENMOD and repeated-measures regression on binary-response data via generalized estimating equations (SAS Institute, Cary, NC).

\begin{tabular}{|c|c|c|c|c|c|c|}
\hline Parameter $^{\mathbf{a}}$ & Estimate & SE & Lower $95 \% \mathrm{CL}$ & Upper $95 \% \mathrm{CL}$ & $Z$ & $P$ \\
\hline Intercept & 0.3006 & 0.6675 & 0.1759 & 0.4253 & 0.45 & 0.652 \\
\hline Season $=$ spring & 0.1568 & 0.6289 & 0.000 & 0.4084 & 0.25 & 0.803 \\
\hline Season $=$ summer & -1.0398 & 0.5470 & -1.2161 & -0.8635 & -1.9 & 0.057 \\
\hline Season $=$ autumn & -1.4835 & 0.6755 & -1.7795 & -1.1875 & -2.2 & 0.028 \\
\hline TH lamps only & 0.1112 & 0.5265 & 0.0000 & 0.2808 & 0.21 & 0.833 \\
\hline TH lamps and HID lamp on constant & 1.1158 & 0.5234 & 0.9448 & 1.2868 & 2.13 & 0.033 \\
\hline Group size & -0.4227 & 0.2124 & -0.4624 & -0.3830 & -1.99 & 0.047 \\
\hline Starting distance & 0.0015 & 0.0009 & 0.0013 & 0.0017 & 1.61 & 0.108 \\
\hline
\end{tabular}

\footnotetext{
${ }^{\mathrm{a}}$ Season $=$ winter and the combination of TH lamps with HID pulsed at $2 \mathrm{~Hz}$ were not estimable from the observational data.
} 
course) the behavioral result can be avoidance or flight. The contrasting and significant contribution to FID of the combination of TH lamps and the HID on constant illumination is thus indicative of the effect of a consistent cue.

We recognize, also, that there was no control for the position of the HID lamp (i.e., lamp elevation, angle, and arrangement of the lighting treatments), relative to the $\mathrm{TH}$ lamps. However, matching the number, as well as position, angle, and beam properties of the 2 lamp types was not possible. Further, both the curvature and varying elevation of a road, as well as vehicle type will affect the perceived angle of light from vehicle lamps. Again, however, we note that there is no indication that DVCs are necessarily influenced by vehicle lamps, much less the position and angle of the vehicle lamps. We contend, therefore, that potential effects of the position of the HID lamp versus the TH lamps on FID were negligible, given that the FIDs for groups exposed to the pulse treatment (involving the HID and TH lamps) were on average shorter than those of the other treatments.

In addition, the negative correlation of group size with FID and positive correlation of start distance during winter, as defined in our experiment, are consistent with behavioral changes in deer populations during late fall and winter. For example, group size in white-tailed deer generally increases during autumn and winter (comprising females, fawns, and yearling fawns), with large, mixed feeding groups occurring in late winter and early spring (Hawkins and Klimstra 1970). Reimers et al. (2006) reported decreased FID in reindeer (Rangifer tarandus), in response to human approach, as group size increased. However, where visual detection of a threat is impeded (e.g., forests), groups of white-tailed deer ( $\geq 3$ individuals) have exhibited greater FIDs than have smaller groups (LaGory 1987).

Notably, we detected no seasonal extremes in group size, though winter groups were generally the largest. We suggest that the negative correlation of group size with FID (during winter and across seasons) is logical given our observations that each animal in a group did not always respond simultaneously. Similarly, Lingle and Wilson (2001) reported that first detectors within a group oriented toward the human approaching (i.e., the threat), whereas group members responded both to the human and other group members.

However, the trends in FID are also indicative that habituation was a factor in our experiment. Though FIDs increased from winter to spring, thus discounting a novelty effect, we observed a decrease across treatments from spring to autumn, as well as a decrease within treatment during the same period. Also, though autumn was significantly and negatively correlated with FID, there was no within-season effect of starting distance, a variable generally positively associated with FID (Lingle and Wilson 2001). Importantly, however, FIDs for deer exposed to TH lamps and the HID lamp set to constant remained distinctive across seasons.
Importantly, the constraints of quantifying behavioral responses by free-ranging deer to vehicle approach added realism to our experimental design. However, though our findings are encouraging relative to the potential for use of vehicle-based lighting to reduce the frequency of DVCs, they must be viewed relative to the experimental constraints versus actual conditions on public roads. Specifically, the delayed response associated with group size is a concern with regard to vehicle approach speed and driver awareness of deer hazards. Further, we collected our data based on a slow approach speed relative to posted speed limits for most public roads in North America, on straight roads, and from deer near the road that were not exhibiting flight behavior prior to our approach. As noted earlier, habitat conditions near a road will affect visibility of potential threats to deer, as well as subsequent behavior.

\section{MANAGEMENT IMPLICATIONS}

Understanding deer response to the separate effects of emission spectrum and spectral irradiance is critical to the design of vehicle lamps intended to reduce DVCs. We suggest that future lamp designs enhance quantum flux from $400 \mathrm{~nm}$ to $537 \mathrm{~nm}$. We also encourage new research to quantify deer FID in response to specific lamp types, thus allowing for control of emission spectrum while varying spectral irradiance via adjustments to input power or use of multiple lamps of the same type. In addition, researchers should attempt to locate multiple herds for new behavioral studies or separate over time experiments involving different lamp types and one herd. Presently, however, we suggest that deer FID can be increased by combining currently available TH and HID lamps, or use of HID lamps alone, to enhance deer detection of an approaching vehicle at night.

\section{ACKNOWLEDGMENTS}

Our work was supported by the NWRC and Precise Flight, Inc., Bend, Oregon, USA. R. Speers, Bowling Green State University (retired), provided technical guidance relative to our lamp metrics. E. Poggiali provided logistical support. We greatly appreciate reviews of earlier drafts of this manuscript by J. Armstrong, R. Beason, J. Belant, E. Fernández-Juricic, T. DeVault, and L. Yako.

\section{LITERATURE CITED}

Allen, R. E., and D. R. McCullough. 1976. Deer-car accidents in southern Michigan. Journal of Wildlife Management 40:317-325.

Bashore, T. L., W. M. Tzilkowski, and E. D. Bellis. 1985. Analysis of deer-vehicle collision sites in Pennsylvania. Journal of Wildlife Management 49:769-774.

Bellis, E. D., and H. B. Graves. 1971. Deer mortality on a Pennsylvania interstate highway. Journal of Wildlife Management 35:232-237.

Biggs, J. S., S. Sherwood, S. Michalak, L. Hansen, and C. Bare. 2004. Animal-related vehicle accidents at the Los Alamos National Laboratory, New Mexico. Southwestern Naturalist 49:384-394.

Burnham, K. P., and D. R. Anderson. 2002. Model selection and multimodel inference- a practical information-theoretic approach. Second edition. Springer, New York, New York, USA.

Conover, M. R., W. C. Pitt, K. K. Kessler, T. J. Dubow, and W. A. Sanborn. 1995. Review of human injuries, illnesses, and economic losses 
caused by wildlife in the United States. Wildlife Society Bulletin 23:407414.

Curtis, P. D., and J. H. Hedlund. 2005. Wildlife damage management fact sheet series. Reducing deer-vehicle crashes. Cornell University Cooperative Extension, Ithaca, New York, USA.

D’Angelo, G. J., R. J. Warren, K. V. Miller, and G. R. Gallagher. 2004. Evaluation of strategies designed to reduce deer-vehicle collisions. Literature review prepared for the Georgia Department of Transportation by University of Georgia, Daniel B. Warnell School of Forest Resources, Athens, USA.

Dean, P., P. Redgrave, and G. W. M. Westby. 1989. Event or emergency? Two response systems in the mammalian superior colliculus. Trends in Neuroscience 12:137-147.

Dukes, T. W. 1969. The ocular fundus of normal white-tailed deer (Odocoileus virginianus). Bulletin of the Wildlife Disease Association 5: 16-17.

Endler, J. A. 1990. On the measurement and classification of colour in studies of animal colour patterns. Biological Journal of the Linnean Society 41:315-352.

Finder, R. A., J. L. Roseberry, and A. Woolf. 1999. Site and landscape conditions at white-tailed deer/vehicle collision locations in Illinois. Landscape and Urban Planning 44:77-85.

Frid, A., and L. Dill. 2002. Human-caused disturbance stimuli as a form of predation risk. Conservation Ecology 6:11. <http://www.consecol.org/ vol6/iss1/art11>. Accessed 1 Aug 2008.

Hawkins, R. E., and W. D. Klimstra. 1970. A preliminary study of the social organization of white-tailed deer. Journal of Wildlife Management 34:407-419.

Hayes, C. L., and P. R. Krausman. 1993. Nocturnal activity of female mule deer. Journal of Wildlife Management 57:897-904.

Hedeker, D., and R. D. Gibbons. 2006. Longitudinal data analysis. John Wiley and Sons, Hoboken, New Jersey, USA.

Hedlund, J. H., P. D. Curtis, G. Curtis, and A. Williams. 2004. Reducing deer vehicle crashes: what works, and what does not. Traffic Injury Prevention 5:122-131.

Helfman, G. S. 1989. Threat-sensitive predator avoidance in damselfishtrumpetfish interactions. Behavioral Ecological Sociobiology 24:47-58.

Hussain, A., J. B. Armstrong, D. B. Brown, and J. Hogland. 2007. Landuse pattern, urbanization, and deer-vehicle collisions in Alabama. Human-Wildlife Conflicts 1:89-96.

Insurance Institute for Highway Safety. 2005. Collisions with deer. Status Report 40(1):4-5.

Jacobs, G. H., J. F. Deegan, II, J. Neitz, B. P. Murphy, K. V. Miller, and R. L. Marchinton. 1994. Electrophysiological measurements of spectral mechanisms in the retinas of two cervids: white-tailed deer (Odocoileus virginianus) and fallow deer (Dama dama). Journal of Comparative Physiology A 174:551-557.

Kammermeyer, K. E., and R. L. Marchinton. 1977. Seasonal change in circadian activity of radio monitored deer. Journal of Wildlife Management 41:315-317.

LaGory, K. E. 1987. The influence of habitat and group characteristics on the alarm and flight response of white-tailed deer. Animal Behaviour 35: $20-25$.

Lingle, S., and F. Wilson. 2001. Detection and avoidance of predators in white-tailed deer (Odocoileus virginianus) and mule deer (O. hemionus) Ethology 107:125-147.

Lung, M. A., and M. J. Childress. 2007. The influence of conspecifics and predation risk on the vigilance of elk (Cervus elaphus) in Yellowstone National Park. Behavioral Ecology 18:12-20.

Marchinton, R. L., and D. H. Hirth. 1984. Behavior. Pages 129-168 in L. K. Halls, editor. White-tailed deer ecology and management. Stackpole, Harrisburg, Pennsylvania, USA.

McCaffery, K. R. 1973. Road-kills show trends in Wisconsin deer populations. Journal of Wildlife Management 37:212-216.

Neitz, J., and G. H. Jacobs. 1989. Spectral sensitivity of cones in an ungulate. Visual Neuroscience 2:97-100.

Reimers, E., F. L. Miller, S. Eftestøl, J. E. Colman, and B. Dahle. 2006. Flight by feral reindeer Rangifer tarandus tarandus in response to a directly approaching human on foot or on skis. Wildlife Biology 12:403413.

Seiler, A. 2005. Predicting locations of moose-vehicle collisions in Sweden. Journal of Applied Ecology 42:371-382.

Seiler, A., J.-O. Helldin, and C. Seiler. 2004. Road mortality in Swedish mammals: results of a driver's questionnaire. Wildlife Biology 10:225233.

Stankowich, T., and D. T. Blumstein. 2005. Fear in animals: a metaanalysis and review of risk assessment. Proceedings of the Royal Society B 272:2627-2634.

Stankowich, T., and R. G. Coss. 2006. Effects of predator behavior and proximity on risk assessment by Columbian black-tailed deer. Behavioral Ecology 17:246-254.

VerCauteren, K. C., and M. J. Pipas. 2003. A review of color vision in white-tailed deer. Wildlife Society Bulletin 31:684-691.

Verme, L. J., and D. E. Ullrey. 1984. Physiology and nutrition. Pages 91118 in L. K. Halls, editor. White-tailed deer ecology and management. Stackpole, Harrisburg, Pennsylvania, USA.

Walls, G. L. 1942. The vertebrate eye and its adaptive radiation. Hafner, New York, New York, USA.

Walther, F. R. 1969. Flight behaviour and avoidance of predators in Thompson's gazelle (Gazella thomsoni Guenther 1884). Behaviour 84: 184-221.

Ydenberg, R. C., and L. M. Dill. 1986. The economics of fleeing from predators. Advances in the Study of Behaviour 16:229-249.

Associate Editor: Nielsen. 